\title{
The placement journey: do year one placement modules support Childhood Studies student's professional development?
}

Dr Zeta Brown, Tracey Edwards and Helen Perkins

University of Wolverhampton, Walsall, West Midlands, WS1 3BD

01384321000

zeta.brown@wlv.ac.uk

$\underline{\text { Tracey.Edwards2@wlv.ac.uk }}$

Helen.Perkins@wlv.ac.uk

Dr Zeta Brown is a lecturer in Childhood, Family and Community Studies at the University of Wolverhampton. She is leader of the Childhood, Youth and Families research cluster for the Centre for Developmental and Applied Research in Education and a member of the Higher Education Pedagogic research cluster. She is an executive member of the British Education Studies Association and the International Society for the Scientific Study of Subjectivity. Zeta has two strands to her research; she researches learning and teaching in Higher Education and the practical implementation of educational agendas in primary education.

Tracey Edwards is a lecturer in Childhood, Family and Community Studies at the University of Wolverhampton. She is Course leader for the BA Childhood Studies and Early Years Teacher Status course. Tracey's research is in the developing professional identity of early years students and she is currently starting her $\mathrm{PhD}$ research on Effective mentoring relationships in the early years workforce.

Helen Perkins is a lecturer in Childhood, Family and Community Studies at the University of Wolverhampton and is Senior Fellow of the Higher Education Academy. Helen served as an expert panel member for the Nutbrown Review of Early Years qualifications. Her current Doctoral research centres on the experiences, knowledge, skills, attitudes and dispositions gained by Level 3 early years student-practitioners in preparation for employment. 


\title{
The placement journey: do year one placement modules support Childhood Studies student's professional development?
}

\begin{abstract}
This study investigated changes made to the Childhood Studies placement journey of one post-1992 University in England. The Childhood Studies degree includes 'practitioner options' that requires students to complete 200 hours placement experience, including 50 hours in year one. In 2014, the participant university responded to this expectation by developing a year one placement module. The study sought to investigate whether the placement module supported the development of student's professional identities in the first year of their studies. The study primarily used questionnaires, with a small amount of interviews and focus groups during 2014-2015. It found three key themes that students associated with their year one placement and their professional development. These were the importance of placement, links made from theory to practice and links from practice to theory. Students did however state disparities in their experiences of placement; especially in the range of responsibilities they were given. Students commented generally on the benefits (to their professional development) of relating theory to their year one practice, but noted frustration that there were minimal opportunities to reflect on practice in module assessments. The study contributes to existing literature by questioning how theory to practice and practice to theory links can be made more explicit in year one programmes.
\end{abstract}

Keywords: childhood studies, early years, professionals, higher education, students. 
The paper aims to explore whether placement modules support the development of Childhood student's professional identities in the first year (level four) of their studies. The paper includes a study carried out in one post-1992 University in England. Whilst the study focuses on one institution, its findings are relatable to differing universities Childhood Studies degrees and relatable placement based programmes. It is therefore important for the literature review to broadly consider the recent political changes that have placed greater importance on Childhood Studies student's placement journey's and their developing undergraduate professionalism in the UK.

\section{Political changes in Higher Education: the importance on placement and professional development in Childhood Studies}

In 2014, Early Childhood Education and Care (ECEC) internationally recognised the quality of early year's staff was not simply about their qualification but the use of pedagogical enhancements in their practice (OECD, 2014). In recognition of this the Childhood studies degree at the university began to evaluate fitness to practice and in response to the Childhood studies bench marks (QAA, 2014) began to incorporate the skills and knowledge required for a range of careers options such as; working with children, their families and the services that support them. The course drew on a range of disciplines such as history, psychology, education, sociology, welfare and social policy.

"The multidisciplinary nature of the subject area means that it equips students with a wide range of subject-specific and generic skills. The intention is to offer steady supported progression towards competence, criticality, independence and reflexivity in both academic and practical work" (QAA, 2014, 5:5.2).

Historically radical changes to the early year's sector were first noted in the National Childcare Strategy (DfES, 1997) and the Children and Young People's Workforce in England (DfES, 2005). Since then significant government changes and policy reports such as the Nutbrown Review (Nutbrown, 2012b) have prompted new developments recommending significant changes to qualifications from college through to undergraduate and graduate course design focusing on raising professionalism within the workforce. This increasing recognition that early years practice should be seen as a profession and be given equal notoriety to primary and secondary teaching has been the focus of much change in the sector. 
The Nutbrown Review (2012a) offered nineteen recommendations to improve the level of qualification of the early years workforce in order to improve quality. Three recommendations focussed on creating a fully qualified workforce including a move towards a graduate-led workforce. Nutbrown recommended the establishment of a new Early Years Teacher role, with Qualified Teacher Status (QTS). 'Having qualified teachers leading practice would raise the status of the sector, professionalism and improve quality' (Nutbrown, 2012b, p.8). The government response to the Nutbrown Review,' More Great Childcare' (DfE, 2013) did not accept the recommendations for a fully qualified workforce or regulate for graduate-led practice; however it did introduce a graduate leadership role, Early Years Teacher Status (EYTS) without the recognition of QTS. The review also emphasised the importance and value of high quality work placements for students to experience first-hand what quality early years practice looks like and to make the connection between theory and practice.

The argument for graduate-led practice is present in a raft of policies. For example the TenYear Strategy: Choice for Parents, Best Start for Children (HMT, 2004) called for a better qualified workforce, suggesting that the level of qualified staff was unacceptable as well as the quality of the qualifications. The Ten-Year strategy asserted that all day-care settings were to be 'professionally led' (HMT, 2004, p.1) without defining what is meant by 'professional'. Since the late 1990s, government policy implementation in ECEC has necessitated a change in the development of early years degree programmes. To encompass the diverse range of professional and practical experiences of those wishing to study at degree level, Early Childhood Studies' benchmarks sought to apply a minimum standard for Honours Bachelor degrees (QAA, 2014). The Quality Assurance Agency (QAA) within England requires that there should be clear links within degree design to support the relationship of theory with practice through professional development and practical experience. However, what is not explicit in this document is the extent to which practical experience is part of the structure, content and delivery of such curricula. It therefore means that this currently varies both regionally and nationally in the UK (QAA, 2014, 2:2.5). Hill (2012) argues that Higher Education Institutions (HEIs) have left these choices to university staff to interpret how to embed employability skills and the professionalisation of graduates to support the workforce.

Individual HEIs' corporate planning, mission statements and student governance therefore can subtly influence course design; as does negotiated employer and stakeholder relevance 
and currency required from vocational qualifications. This can, therefore, create further local and national variance in course design, student experience and vocational breadth in early years' degrees. Kendall et al. (2012) argue that the construction of knowledge is determined by course designers and regulators like QAA and the Office for Standards in Education (Ofsted). Urban (2008) argues that the prevailing habitus of ECEC influences professional self-worth and requires careful thought in training design. The problem has been compounded by the plethora of policy initiatives and regulation that advocated for a professional workforce yet failed to regulate in order to achieve that goal (Campbell-Barr, 2014; DfE, 2014; DfE, 2013e; Nutbrown, 2012a; 2012b). These problems are not easily resolved through technical processes, they are messy and confusing (Urban, 2008). A view echoed by Bertram and Pascal (1999) when reviewing ECEC policy in England for the Organisation for Economic Cooperation and Development (OECD). They noted overtime, the absence of a nationally coordinated ECEC policy had created a wide range of different systems of provision under different authorities and regulations. This diversity and complexity has made concise explanations to an international audience not familiar with the UK ECEC system challenging for the authors (p.6). Subsequent policy initiatives have not improved this situation. In 2016 English ECEC policy remains disconnected and confused, particularly in terms of the workforce and their qualifications. It is still possible to work in ECEC without having any relevant qualifications (DfE, 2014).

In 2013 the Childhood Studies team at the participant university made significant changes to course design in response to the Early Childhood Studies QAA benchmark. The Childhood and Family Honours Degree was revalidated to facilitate two new and more refined degree designs. The first - 'Family and Community studies' - focused on the breadth of childhood and adolescence within the community. The second was designed for students who wanted to study childhood (0-11 years) and is the focus of this current research. The 'Childhood Studies Degree,' was strongly influenced by QAA benchmarks and the National College for Teaching and Learning (NCTL). Whilst similar routes are offered in other HEIs, the university's offer is subtly different in that it includes 'practitioner options', meaning that students who have completed their degrees, and have GCSE maths and English, qualify as level three practitioners in early years settings. Throughout the Childhood Studies degree, students were expected to complete a minimum of 200 hours placement - ideally 50 hours in Year 1, 100 hours in Year 2 and 50 hours in Year 3. To facilitate 'practitioner options' students are assessed in placement through Year 2 module. To further strengthen acquisition 
of the university's 'graduate attributes', employability skills and capabilities, a Year 1 placement module was validated by the participant university in 2014 that linked to the placement experience from the beginning of the course.

\section{Developing professionalism: the undergraduate journey}

There has been extensive research on professionalism in the early years and in the primary sector (e.g. Hargreaves, 2003; Sachs, 2001; Simpson, 2010) but that is not the focus of this paper, which instead describes students' development of professionalism during undergraduate study. Stronach and colleagues (2003:125) argue that the development of the 'professional self' happens within the 'contradictions and dilemmas' of students own experiences. Brock (2006) developed a concept of the Year 3 'professional student' that can be applied to HE. This concept is linked to ideas of developing professionalism in the early years workforce being associated with 'attitude, ideology and passion':

...the importance of students developing qualities and skills associated with professional behaviour and professionalism [is a key concept in] the development of a professional, qualified ECE workforce. However, the professional student depends on the curriculum, the ability to develop reflective practice and a range of work place experiences, as well as the quality of the college-based teaching Brock (2006: 430).

Brock places importance on the quality of teaching and the curriculum, as well as the placement experience. Sachs (2001) refers to the benefits students can gain from HE in developing skills in self-awareness and reflection. The in-depth knowledge and reflective skills of HE students are seen as key to professionalism and as supporting students in developing greater self-confidence in practice (Hughes and Menmuir, 2002). HE teaching has been praised for the space it offers to reflect on the ways theory can be applied in practice (Goodfellow, 2004). Mathers and Smee (2014) also argue that graduates make a significant difference to outcomes for children, particularly those in the most disadvantaged areas. This suggests that graduates have a level of knowledge and skills beyond the technical, and potentially conferring professional status, as with the EYPS (CWDC, 2006) and the Early Years Teacher Status (EYTS) introduced in 2013.

There is however concerns that the placement experience can become distant to teaching and this may hinder professional development. Urban (2009) warns that ECEC should not focus 
on evidence-based practice (because evidence may be distanced from practitioners and tutors) and instead reflects on the benefits of practice-based evidence. These include, 'creating new understanding and 'learning from success'... and cherishing unexpected outcomes and surprises' (Rosenfeld and Sykes, 1998: 3). The combination of work-based practice alongside theory and knowledge development is acknowledged good practice in developing professional practitioners (Campbell-Barr, Georgeson, \& Varga, 2015; Nutbrown, 2012b; Urban \& Vandenbroeck, 2011) and is reflective of the students his study. Dyer and Taylor (2012: 558) also acknowledge that the nature of placements may affect outcomes and the 'development of competences' by students. The quality of placement is important (Nutbrown, 2012b) and therefore greater emphasis needs to be placed on HE and placement provider relationships.

Schon (1983) argued that educational practice involves continuous reflection and creation of new understanding. To tackle the divide that can occur between theory and practice, Schon concluded that theory and research should be seen as practice. For Reed, Tyler and Walker (2015) reflection includes considering personal experiences, values and attitudes and broader professional reflections on observed and implemented practice. Colley (2006: 773) considers the development of students' 'vocational habitus' which is '... a powerful aspect of the vocational culture: the combination of idealised and realised dispositions to which students must orient themselves in order to become the "right person for the job". Professional attributes that include being a good reflective listener, being able to identify and share good practice, being non-judgemental in their support offer chance to increase this vocational habitus (Reed, Taylor and Walker, 2015; Colley, 2006; Brock, 2006).

However, Vincent and Braun's (2011) research reflects critically on the versions of professionalism offered in Further Education (FE). This may also be relevant to HE and/or students' perspectives of ECEC on entry to HE. They found that students related professionalism narrowly to generic 'professional' behaviours, such as reliability and punctuality. Students valued learning about theory that they could relate directly to practice, including legislation and policy guidelines. Moreover, students did not consider professionalism as a body of knowledge and instead emphasised working with children as being a matter of 'common sense'. The researchers concluded that they had, in many cases, 'fragile learner identities', their vocational habitus was constrained and they were unlikely to see further academic study as suitable. Interestingly, Egan (2004) found that students at the beginning of their second year of $\mathrm{HE}$ teacher training also expressed their 'professionality' in 
terms of personal qualities, such as ability to work flexibly, rather than as the development of professional knowledge or skills. Asked to consider their future professional selves, students noted areas of professional development that then included personal attributes, personal interests or values, theoretical knowledge and professional knowledge. Egan (2004) notes that this praxis is not surprising as aspects such as professional knowledge are what students hope to acquire during the course. Furthermore, of the professional attributes mentioned, Egan (2004) identified the need to develop confidence and resourcefulness, concluding that, to some extent, individual characteristics exist on entry to programmes, as do assumptions about teaching and practical applications.

The increasing recognition of professionalisation in the workforce (Nutbrown, 2012b) is evident in the literature review. Changes in recognition and policy have seen increasing importance placed on undergraduate placement experience, including placement in the first year of study (QAA, 2014) and Childhood Studies student's professional development (Urban, 2008). In research there are evident links made between student's placement experience, their experience in Higher (and/or Further) education and their professional development. Brock (2006) concludes that professional development depends on a range of placement experiences and good quality teaching. Students need to gain a good quality placement experience to develop their vocational habitus and in turn, develop professional attributes such as in-depth practical knowledge and reflective skills (Hughes and Menmuir, 2002; Nutbrown, 2012b). However, students appear to have differing perspectives on how they define professionalism and the importance they place on placement and teaching (Egan, 2004; Vincent and Braun, 2013). The study described in this paper investigated student's perspectives on whether the first year placement module (in one institution) supported Childhood Studies student's professional development.

\section{Methodology}

In the interpretivist-qualitative research approach on which this article is based, there is a focus on engaging with the positions of the individuals researched (Basit 2010). In searching for meaning, interpretivist researchers look beyond an individual's actions and engage with participants' positions in the social world (Burton and Bartlett 2009). The approach is, therefore, subjective and engages with a more personable, people-based form of research. The interpretivist focus of the study was on the participants' positions, acknowledging that these positions and one's actions can alter over time and be dependent on situational 
circumstances. This means that these findings cannot be overgeneralised; findings should be compared and contrasted between different periods of time or different places (Cohen et al., 2011).

Shacklock and Smyth (1998:6) stated 'reflexivity in research is built on an acknowledgement of the ideological and historical power dominant forms of inquiry exert over the researcher and the researched'. As the researchers in this study were also lecturers it was important to consider researcher bias and also how students were approached and became part of the research. Data collection methods were carefully selected to ensure that students had the opportunity to participate and keep their identities hidden from researchers by using questionnaires. Interviews and focus groups were offered as an option and only students who volunteered participated in the data collection. Ethical consent was sought and was given by the researchers' ethics committee. Informed consent was acquired by all participants for each data collection method and participants were guaranteed confidentiality and anonymity.

The study investigated Childhood Studies undergraduate students' positions on whether there was effective support for professional development in the first year of study. The research questions focused on students' expectations of developing as professionals on entry to the course, the qualities they brought to the course, such as their personal/professional attributes, and their perspectives on whether they developed as professionals in the first year of study. The data collection schedule and questions asked were carefully designed to ascertain students' positions across the academic year. At each stage of data collection, the entire cohort was asked if they would like to take part and those who volunteered participated. Out of 60 students, 40 agreed to complete questionnaires in their second week of study. The majority of the participants were female, with only two male participants. This is reflective of the percentage of men working in the ECEC sector (Nutbrown, 2012b). The age range of these participants was 18 to 36 years. The age, gender and ethnicity were not considered for analysis in this sample; relevance for this sample is defined by the choice of early year's degree taken. In semester two the same cohort was asked to take part in interviews. In total 13 students volunteered to participate, however 9 students asked to be seen as a focus group rather than be interviewed individually. The cohort was asked at the end of the academic year to complete a second questionnaire and 25 students volunteered to participate. Data collection in the second semester focused on students reflecting on their first year experiences and whether they considered this programme to support their professional development. This 
data was of particular interest to the participant university as it was the first year in which placement was a mandatory component from the beginning of the course.

Many of the questions used did not ask students directly about their professional development. This was because students might not have related the skills they developed specifically to their professional development and, as research has found, students define professionalism in different ways (Stronach et al. 2003). Instead many of the questions were focused more generally on students' experiences in their studies, including placements and in lectures, and what skills they believed they had developed throughout their first year of study. In this way, links between students' skills and professionalism were not imposed on these students; instead their comments are linked to these key skills in the research findings.

It is however important in reflexivity to consider the study's limitations especially due to these power dynamics. Lam, Wong and Leung (2007:93) state 'reflexive learning is a process of interpretive discovery embedded in experience... [the] process invariably leads to increased self-awareness, increased sensitivity to the environment and a change in conceptual perspective'. The study used questionnaires, interviews and focus groups throughout one academic year. It was hoped by the researchers that the questionnaire data would provide a preliminary means of understanding student's perspectives that then could be explored further in interviews and focus groups. However, students in this study were more comfortable being included in the questionnaire data collection than in interview and focus groups. It can be purported that this may be because of the power dynamics between lecturer and students, or that students felt more comfortable with the anonymity of questionnaires in their first year of study. It nevertheless led to a significant difference in participant numbers across the data collection methods. On analysis of the data it became clear that the questionnaire data provided a more in depth analysis of the range of student's perspectives. The questionnaires therefore became the main data collection method in this study. Instead of focusing on individual perspectives, this study moved to focusing on commonalities amongst these individuals' perspectives.

The questionnaire and interview data were analysed by carrying out extensive qualitative coding of all participants' responses. The process of coding was used to find commonalities of perspectives across the participants to develop themes (Braun and Clarke, 2006). In order to find commonalities of perspective, the coding process sought to find key words that were identified by more than one participant. For instance, when asked what skills students 
developed during their placement, key words included 'confidence', 'understanding', 'experience' and 'knowledge'. These commonalities of perspective developed three key themes that linked directly to students' professional development in this study. These were the importance of placement, links made from theory to practice and links made from practice to theory. These themes are presented using verbatim quotes from participants. They are chosen to represent a range of examples assigned to the same theme.

\section{Findings}

\section{Disparity in placement experiences: the impact on students' developing professional identities}

On entry to the course students emphasised their high expectations of their first year placement experiences. They expected that, as HE students, they would have hands-on experiences that reflected their HE status. One student said, 'hopefully [I will have a] handson approach as when studying for sixth form I felt the jobs on offer was jobs the nursery staff didn't have time to do therefore as I am studying a degree there will be more of a formal role due to the maturity of myself as a student at university.' In total 21 students commented on benefits they experienced from attending placements in their first year of study. Students reported developments in both the qualities and the skills they gained in placement. Some students mentioned more than one developed quality or skill and are therefore represented more than once in the themed data analysis. The qualities and skills included knowledge and understanding, confidence, professional skills and experience. Whilst there were commonalities amongst the developed qualities and skills, the specific professional developments differed. For instance, thirteen students commented on developing qualities and skills that were associated with knowledge and understanding. However, the knowledge and understanding they gained from placement was diverse. One student commented on further understanding children and how play benefits them. Another stated, 'I have gained knowledge [of] how the EYFS is put into practice'. Students mentioned other areas of knowledge and understanding that included a wider knowledge of policies and knowledge of how a school is run in a low socio-economic area. 
Equally, six students that mentioned the development of confidence in placement discussed these developments in differing ways. Some mentioned generally developing confidence, where others mentioned gaining confidence in specific areas, such as planning. Three students mentioned the development of professional's skills that included generally learning skills by observing professionals in practice. One student stated, 'I have developed my communication skills as I have to adapt my way of teaching to suit the children'. Three students also mentioned experience in placement as one of their benefits. One student linked their placement experience to theory in lectures by stating, 'more experience, which helps to understand the work in seminars'.

Whilst students mentioned benefits to experiencing year one placement, they also mentioned disparities in their experiences. Not all students had positive placement experiences. Two students in interview discussed their difficulties. One explained that she didn't get a chance to interact with the children and didn't feel part of the team: 'I tried primary and I hated it'. Another described her time as sticking notes in books. It was 'okay but not great as I can't do a lot in the classroom. I spent four hours sticking in books...'. Students also discussed finding out that their experiences differed when discussing their experiences with peers. In the questionnaire data there was a significant variation of student experiences that ranged from supporting the daily running of settings. These experiences included looking after children, working and communicating with parents, nappy changing and feeding in early year's settings. In key stage one and two students mentioned supportive roles such as assisting the teacher, recording children's progress and supporting forest school. There were some students who experienced a placement experience that resembled the high expectations discussed earlier. One student in interview said she was taken seriously as there was an assumption she would know more as an HE student. Another said she had learnt a lot from her nursery placement, especially in learning through play. Because she was referred to as a teacher, she felt like a teacher. In the questionnaire data some students also experienced planning and leadership roles. In the early years this included planning and leading activities such as phonics. In key stage one and two this included students leading on activities, teaching small groups and leading reading sessions.

\section{The professional benefits of linking theory to practice: students' generalised acknowledgment of links in their first year of study.}


At the end of the academic year students were asked how their taught content supported their practical experiences. Seventeen respondents stated that placement supported them linking theory to practice. The commented mostly provided generalised comments on the 'process' of doing so. Ten students mentioned generalised links that included, "I feel I have been able to put theory into placement to make me a better practitioner", "it has been good to apply my knowledge into my workplace" and "[it] enabled me to apply the theory to my work and plan activities appropriately". Whilst these are generalised links, students did mention being influenced by theory in the way they carried out their practice. Benefits of linking theory to practice were mentioned in students' questionnaires and interviews. These included the development of their practitioner role, understanding their duty of care and supporting the development of their professional identities. Four students mentioned that linking theory to placement supported them in understanding childhood. One stated, "it has taught me why children do certain things", another said, "[it] made me understand what challenges there are when working with children, how to recognise different issues with children and their families".

Interestingly, four students specifically mentioned using safeguarding theory in practice. One student said, "safeguarding has taught me to be aware of any potential risks", another stated, "the modules that incorporate safeguarding have done". Students in two focus groups also mentioned the benefits of implementing safeguarding policies in practice. One said that she had used her initiative to ask the safeguarding officer if she could look at the setting's safeguarding policy. It is interesting that safeguarding policies and procedures were specifically mentioned. It is obviously fundamentally important for students to understand this theory. However, there is a lot of theory introduced in year that can be linked directly to practice. This theory usually includes child development, developing professionalism and information on the EYFS and National Curriculum. However, none of the year one students mentioned any other specific theory than the four students who specifically discussed safeguarding. This may be that they see the significance of this theory, or that this theory provides easier links between theory and practice than the rest of the first year's theory.

The professional benefits of linking practice to theory: students call for greater links to be made in their first year of study 
Students were asked at the end of the academic year if they had reflected on their placement experiences in their academic writing. Sixteen students commented on this question, eight find practice to theory links in only one module and one further student found links in two modules. These modules were 'Developing Professionals in the Early Years' (the module linked to the mandatory placement) and again the safeguarding module. Interestingly, these two modules specifically ask for placement observations or links to be made in the modules assessments. One student stated, "it has definitely helped in regards to developing professionals, as I secured a high grade and was over the moon with receiving $76 \%$, considering it was only the second time ever in a placement". Another said, "It's helped with safeguarding" and one said they were able to use examples of practice in their developing professional's assignment. Students also appeared to be frustrated that they did find greater links present between practice and assessment. One student stated "only helped me with one module...'Developing professionals'. Other assignments I wasn't able to incorporate placement experiences into as it wasn't relevant". These students only considered specific links to their placement as links between practice and theory. They did not consider whether their placements had influenced their academic writing in any other modules. Three students stated that no links or minimal links had been made and did not make specific links to module assignments. There were only four students who mentioned general links (without stating a specific module) that helped them apply their personal experiences. One student said, "I feel it has helped a lot, to allow me to understand what I am writing about, and allow me to put an example to theory", another said, "I feel this had helped a lot so I could apply personal experience". These students may have been thinking of a specific module without stating it, or may have been considering links made between practice to theory across modules.

\section{Discussion}

In contrast to Vincent and Braun's (2011) research, students considered a broader concept of their developing professionalism that did not focus on 'professional behaviours'. Egan (2004) noted areas of professional development that students hoped to achieve in their second year. These included personal attributes, personal interests or values, theoretical knowledge and professional knowledge. In these findings students, on entry to their studies, believed they would professionally benefit from first year placement, concentrating on the 
development of personal attributes (such as confidence) and professional knowledge (including considering theory in practice). Moreover, examples of experiences students hoped to gain were comparable to the responsibilities of professionals in practice and included marking work, filing paperwork, planning and leading activities and working closely with children to support their learning and development.

Egan (2004) identified the need for students to gain confidence and concluded that, to some extent, individual characteristics exist on entry to programmes. However, students in this study who commented on confidence specifically associated this development with aspects of their placement. They did not focus on the individualised characteristics that they held that could support them in their professional development. According to Colley (2006) students develop a 'vocational habitus' by learning the idealised and realised dispositions they must have in practice. In these findings these students are beginning to develop an understanding of their profession and the dispositions they must possess. However, their 'vocational habitus' appeared to be influenced by the experiences they were subject to in practice. Students in these findings commented on disparity in their placement experiences that they felt disadvantaged some of them during their first year studies. Dyer and Taylor (2012: 558) acknowledge that the nature of a placement can sometimes affect outcomes and 'development of competences' in students. In comparison to the Nutbrown (2012b) the quality of the placement setting is of paramount importance. There is therefore a need to regulate the placement experience to ensure consistency across experiences. Currently, visits to settings in the participant university occur only in year two. With hindsight, visits may be necessary for first year monitoring too. However, student's expectations also need to be considered further here. What should level four students expect from their placements? Should they expect a hands-on experience that reflects their HE status? Does it depend on the individuals professional characteristics? These are questions that need to be further explored. The findings of this study indicate that level four students need to be further informed on what is expected of them in placement and what they should expect from their placements.

Students acknowledged minimal links to specific moments where theory was considered in practice, with the exception of those who commented on considering safeguarding legislation. This finding reflects Vincent and Braun's (2011) research where they found levels two and three students in FE valued learning that they could relate directly to practice, including legislation and policy guidelines. This was true for those who gave specific examples. However, links beyond safeguarding were seldom made. 
Hughes and Menmuir (2002) comment that the in-depth knowledge and reflective skills of HE students are seen as key to developing professionalism and support students in developing greater self-confidence in practice. In these findings, first year students made links but those they mentioned were generalised or specific to safeguarding legislation. It may be that, in the first year, students need to become aware of the 'process', later developing these initial links further in their second year. There are regional and national differences in the extent to which practical experiences are part of HE Childhood Studies programmes (QAA, 2014). Until 2014-2015 placement was not a mandatory component of first year studies and so students were not expected to make such links until their second year. So the acknowledgement of such links may be sufficient in the first year of study.

Brock's (2006: 430) concept of the 'professional student' argues that '...the professional student depends on the curriculum, the ability to develop reflective practice and a range of work place experiences, as well as the quality of the college-based teaching'. The 'professional student' in Brock's research is a student at level three in FE and so naturally has a more vocationally centred concept of education. However, reflective practice is important in HE; Sachs (2001) refers to the benefits students gain by attending HE and developing skills such as self-awareness and reflection. Students in these findings felt discontent about the amount of opportunity they had to reflect on their practice. Importantly, students found the majority of modules were taught in isolation from their practical experiences. However, this was in reference to specific links being made to practice in module assessment and academic writing. To enhance opportunities for reflection it may be necessary to further discuss links made between practice and theory throughout first year modules (including assessment), to support students in developing professionalism in practice.

\section{Concluding statements}

The findings of the study indicate that embedding mandatory placement in the first year supports students' developing professionalism. The value students assign to their placement experiences is evident in current research. However, this research contributes to existing knowledge by specifically considering the professional development value first year students assign to theory in placement and to placement in taught sessions. Ensuring links from theory to practice and from practice to theory seems to reflect both common sense and a necessary priority in Childhood Studies courses as well as all courses that have practice- 
based placement learning. However, there may be evidence of such links in course and module design, but are they evident to students? Students in this research referred to links when they were explicitly identified in their summative assignments. Links made in weekly out of class activities or generally to the placement module were not considered in their reflections. This is intriguing as some of the first year modules, including the placement module, ask students to observe practice and write reflections on how it relates to relevant theory as out of class activities. This finding may be because the researchers of this study asked students about links made between their practice reflections and academic writing. However, students specifically considered practical reflections in their module assessments, rather than in their academic writing generally throughout the module. It appears that students therefore expected to directly reflect on observations in their level fours assessments. These findings therefore represent a need for courses to thoroughly explain and support the differing ways students can link their theory to practice and practice to theory throughout their course and within specific modules from the beginning of their studies.

Moreover, these findings suggest that students had begun to develop professionally by developing qualities and skills that included knowledge and understanding, confidence and professional skills. However, it is debatable whether this is sufficient at this level of study. Should level four students be developing their professional identities further at this stage in their post-compulsory studies or is this year an introductory step towards the degree? These questions are perhaps broader than the focus of this paper, however they are necessary questions in order to consider the professional development expectations of each level of study.

As QAA (2014) states, there are regional and national variations in course design in Childhood Studies undergraduate programmes. Therefore, it is important for these findings to be considered in the context of the Childhood Studies programme at the participant university. The findings have influenced two important areas in this level of course design:

- The need for consistency in first year placements. The course management team is considering whether regulation needs to be in place that is similar to the second year of study. They are also moving the iteration of the placement module to semester 2 to give students time to access placements.

- While the course design addresses QAA requirements, it does not necessarily meet the needs of first year students. Students called for more reflective opportunities to 
support their developing professional identities. In the course design, stronger links have been embedded between practice to theory in the first year and theory and practice in the second year to encourage further development of students' professionalism in practice. By moving the placement module to semester 2 it is also hoped that students will have greater opportunity to acquire underpinning knowledge in semester 1 that can be linked to placement in semester 2 .

\section{References}

Basit, T. 2010. Conducting research in educational contexts. London: Continuum international Publishing group.

Braun, V., \& Clarke, V. (2006). Using thematic analysis in psychology. Qualitative Research in Psychology, 77-101. doi:10.1191/1478088706qp063oa

Bertram, T., \& Pascal, C. (1999). The OECD Thematic Review of early Childhood Education and Care: Report for the United Kingdom. University of Worcester. Paris: OECD. Retrieved May 2014, from http://www.oecd.org/dataoecd/48/16/2479205.pdf

Brock, A. 2006, in Musgrave, J. 2010. Educating the Future Educators: the quest for professionalism in early childhood education. Contemporary Issues in Early Childhood. 11(4): 435-42.

Burton, D. and Bartlett, S. 2009. Key Issues for Education Researchers. London: Sage Publications Ltd.

Campbell-Barr, V. (2014). Construction of Early Childhood Education and Care Provision: negotiating discourses. Contemporary Issues in Early Childhood, 15(1), 5-9. doi:10.2304/ciec 
Campbell-Barr, V., Georgeson, J., \& Varga, A. (2015). Developing Professional Early Childhood Educators in England and Hungary: Where Has All the Love Gone? European Education, 47(4), 311-330. doi:10.1080/10564934.2015.1100451

Cohen, L., Manion, L., Morrison, K. and Bell, R. 2011. Research Methods in Education. ( $7^{\text {th }}$ edn). London: Routledge.

Colley, H. 2006 in Vincent, C. and Braun, A. 2011. 'I think a lot of it is common sense ...' Early years students, professionalism and the development of a 'vocational habitus'. Journal of Education Policy. 26(6): 771-85.

DfES (1997) National Childcare Strategy. 'Meeting the Childcare Challenge'. London: Stationery Office.

DfE. (2013). More great childcare: raising quality and giving parents more choice. London: HMSO. Retrieved July 2013, from https://www.gov.uk/Government/uploads/system/

DfE. (2014). The Early Years Foundation Stage. London: DfE. Retrieved August 2014, from https://www.gov.uk/Government/publications/early-years-foundation-stageframework--2

Dyer, M. and Taylor, S. 2012. Supporting professional identity in undergraduate Early Years students through reflective practice, Reflective Practice: International and Multidisciplinary Perspectives, 13(4): 551-63.

Egan, B. 2004. Constructing a professional identity: some preliminary findings from students of early years education. European Early Childhood Education Research Journal. 12(2): $21-32$.

Goodfellow, J. 2004, in Osgood, J. 2010. Reconstructing professionalism in ECEC: the case for the 'critically reflective emotional professional'. Early Years: An international Research Journal. 30(2): 119-33.

Hargreaves, A. 2003, in Day, C. and Smethem, L. 2009. The effects of reform: Have teachers really lost their sense of professionalism? Journal of Educational Change. 10(-): 141-57. 
Hill, F. 2012. Briefing paper for teaching and learning summit on employability: National Policy Context and HEI strategies for student employability. National co-ordinating centre for public engagement. The Higher Education Academy.

HMT. (2004). Choice for Parents: the Best Start for Children. London: Her Majesty's Treasury.

Hughes, A. and Menmuir, J. 2002, in Osgood, J. 2010. Reconstructing professionalism in ECEC: the case for the 'critically reflective emotional professional'. Early Years: An international Research Journal. 30(2): 119-33.

Kendall, A., Carey, D. Cramp, A. and Perkins, H. 2012. Barriers and solutions to HE progression for Early Years' practitioners, Journal of Vocational Education \& Training, 64(4): 543-60.

Lam, C. Wong, H. and Leung, T. (2007) An Unfinished Reflexive Journey: Social Work Students'Reflection on their Placement Experiences. 37(-),pp.91-105.

Mathers, S., \& Smee, R. (2014). Quality and Inequality: Do three- and four-year-olds in deprived areas experience lower quality early years provision? London: Nuffield Foundation. Retrieved November 2014, from http://www.nuffieldfoundation.org/sites/default/files/files/Quality_inequality_childcare_math ers_29_05_14.pdf

Maxwell, J. (2010) Using Numbers in Qualitative Research. Qualitative Inquiry. 16(6),pp.475-482.

Nutbrown, C. (2012a). Review of Early Education and Childcare Qualifications: Interim Report. London: Department for Education. Retrieved March 2012, from https://www.gov.uk/Government/uploads/system/uploads/attachment_data/file/180927/Revie $\underline{\text { w_of_early_education_and_childcare_qualifications_-_Interim_report.pdf }}$

Nutbrown, C. (2012b). Foundations for Quality: The independent review of early education and childcare qualifications Final Report. London: Department for Education. 
OECD (2014), Education at a Glance 2014: OECD Indicators, OECD Publishing. http://dx.doi.org/10.1787/eag-2014-en

Osgood, J. 2010. Reconstructing professionalism in ECEC: the case for the 'critically reflective emotional professional'. Early Years: An international Research Journal. 30(2): 119-33.

QAA, 2014. Subject Benchmark Statement Early Childhood Studies. Gloucester: The Quality Assurance Agency for Higher Education.

Reed, M., Tyler, T. and Walker, R. 2015. The Undergraduate Journey, in Reed, M. and Walker, R. (eds) 2015. A Critical Companion to Early Childhood. London. Sage: 15-23.

Rosenfeld, J. M. and Sykes, I. J. 1998, in Urban, M. 2010. Rethinking Professionalism in Early Childhood: untested feasibilities and critical ecologies. Contemporary Issues in Early Childhood. 11(1): 1-7.

Sachs, J. 2001. Teacher professional identity: competing discourses, competing outcomes. Journal of Education Policy. 16(2): 149-61.

Shacklock, G. and Smyth, J. (1998) Being Reflexive in Critical Educational and Social Research. London: Falmer Press.

Schon, D. A.1983, in Urban, M. 2010. Rethinking Professionalism in Early Childhood: untested feasibilities and critical ecologies. Contemporary Issues in Early Childhood. 11(1): $1-7$.

Simpson, D. 2010. Being professional? Conceptualising early years professionalism in England. European Early Childhood Education Research Journal. 18(1): 5-14.

Stronach, I., Corbin, O., McNamara, S., Stark, S. and Warne, T. 2003, in Osgood, J. 2010. Reconstructing professionalism in ECEC: the case for the 'critically reflective emotional professional'. Early Years: An International Research Journal. 30(2): 119-33. 
Urban, M. 2008. Dealing with Uncertainty: challenges and possibilities for the early childhood profession. European Early Childhood Research Journal. 16(2): 135-52.

Urban, M. 2009, in Urban, M. 2010. Rethinking Professionalism in Early Childhood: untested feasibilities and critical ecologies. Contemporary Issues in Early Childhood. 11(1): $1-7$.

Urban, M., \& Vandenbroeck, M. (2011). Competence Requirements in Early Childhood Education and Care. University of East London, Cass School of Education and University of Ghent. European Commission, Directorate-General for Education and Culture. Retrieved January 2015, from http://ec.europa.eu/education/policy/school/competences_en.htm

Vincent, C. and Braun, A. 2011. 'I think a lot of it is common sense...'Early years students, professionalism and the development of a 'vocational habitus'. Journal of Education Policy. 26(6): 771-85. 